\title{
Avaliação, Classificação e Decisões sobre Embriões In Vitro: As (Re)Apropriações das Normas pelos Embriologistas ${ }^{1}$
}

\author{
Evaluation, Classification and Decision-Making on In Vitro \\ Embryos: The (Re)Appropriations of Norms by Embryologists
}

\section{Catarina Delaunay}

Centro Interdisciplinar de Ciências Sociais, Universidade Nova de Lisboa, Lisboa, Portugal

\section{Luís Gouveia}

Centro Interdisciplinar de Ciências Sociais, Universidade Nova de Lisboa, Lisboa, Portugal

\section{RESUMO}

Este artigo descreve, analisa e discute as formas de relação dos embriologistas com as normas padronizadas que orientam a sua prática profissional no âmbito das técnicas de Procriação Medicamente Assistida em termos de avaliação, classificação e tomada de decisão sobre o embrião humano criado in vitro. Com base em entrevistas realizadas com embriologistas de centros públicos e privados de Procriação Medicamente Assistida, problematizamos as formas de adesão e conformação à governança pela norma, ou, como contraposto, às modalidades de composição, adaptação, negociação, ressignificação e crítica das normatividades estandardizadas por parte desses profissionais de saúde de acordo com os seus próprios esquemas cognitivos, saberes experienciais e padrões normativos. Sistematizamos os critérios usados na decisão sobre os embriões a transferir, congelar ou descartar e propomos uma gramática de lógicas em termos de atitudes e

1 Esta pesquisa foi financiada por Fundos Nacionais através da FCT — Fundação para a Ciência e a Tecnologia, no âmbito do projeto ETHICHO - Coreografias ético-ontológicas: Formas de objectivação e avaliação do embrião humano in vitro no contexto da Procriação Medicamente Assistida e da Investigação Científica (Ref. PTDC/ SOC-SOC/29764/2017). 
posicionamentos, mais ou menos rígidos, dos embriologistas diante dos standards e guidelines de avaliação e da classificação dos embriões.

Palavras-chave: Embrião humano in vitro, Normas padronizadas, Sistemas de avaliação e classificação embrionária, Áreas de jurisdição e pericialidade, Controvérsias sociotécnicas.

\section{ABSTRACT}

This article describes, analyzes and discusses the forms of relationship between embryologists and the standardized norms that guide their professional practice in the context of assisted reproductive technologies, namely in terms of evaluation, classification and decision making on the human embryo created in vitro. Starting from interviews with embryologists exercising their professional activity in public and private centers of assisted reproductive technology, we problematize the ways of adhering to and conforming to the governance by norm, or, as a counterpoint, the modalities of composition, adaptation, negotiation, resignification and criticism of the standardized norms by these health professionals according to their cognitive schemes, experiential knowledge and normative standards. We systematize the criteria used to decide on embryos to be transferred, frozen or discarded. and propose a grammar of logics in terms of attitudes and positions, more or less rigid, of embryologists concerning standards and guidelines for embryo assessment and classification.

Keywords: Human embryo in vitro, Standardized norms, Embryo assessment and classification systems, Jurisdiction and expertise areas, Sociotechnical controversies

\section{INTRODUÇÃo}

A transição histórica da medicalização para a biomedicalização, através da integração social de inovações e das intervenções altamente tecnocientíficas, ampliou e reconstituiu tanto a organização como as práticas da medicina contemporânea, passando do controle sobre os fenômenos biomédicos para a sua transformação (CLARKE et al., 2003). Os corpos são assim transformados para incluir novas propriedades, enquanto novas identidades tecnocientíficas individuais e coletivas estão a ser produzidas (CLARKE et al., 2003). Desse modo, a biomedicalização, no âmbito da reprodução medicamente assistida, produz um novo ator e identidade 
tecnocientífica: o embrião in vitro ${ }^{2}$.

No início do século XX, a sistematização dos estágios do embrião (estágios Carnegie) contribuiu para a mecanização das fases de desenvolvimento embrionário em estreita articulação com a dimensão tempo; a posterior mudança para a escala genética introduziu um sentido de vida biológica perfeitamente planeada, em termos da presumível trajetória do embrião (DICAGLIO, 2017). Conforme a autora, a biomedicina e as novas tecnologias induzem à tomada de decisão com base nessa antecipação.

A embriologia clínica surge no contexto da assistência médica à reprodução. Ela está associada à construção de formas padronizadas de governança (i.e, de governança pela norma) e à atividade laboratorial, envolvendo um conjunto de parâmetros, instrumentos e protocolos de controle, regulação e avaliação das condutas. Em Portugal, essas práticas e dinâmicas regulatórias do exercício da própria profissão de embriologista remetem para determinados regimes normativos e simbólicos que, por um lado, emanam das instâncias superiores de regulamentação, como o Conselho Nacional de Procriação Medicamente Assistida (CNPMA) e a European Society of Human Reproduction and Embryology (ESHRE); e, por outro, são diferentemente interpretados e incorporados na sua prática concreta pelos próprios profissionais. A criação e consolidação de critérios avaliativos e qualificadores do embrião nos seus diferentes estágios remete para uma adesão e conformação cega ao standard ou, pelo contrário, envolve o reconhecimento da legitimidade de outras formas de conhecimento ("o saber de experiência feito") ou critérios complementares (mais gerais e de contexto) como fundamento para a tomada de decisão.

Neste artigo, respondemos às seguintes questões:

1) Quais são as normas internacionais adotadas pelos embriologistas quanto às definições

2 A criação do embrião in vitro potencia e complexifica o problema da fragilidade das fronteiras relativas à condição do ser humano, constituindo um objeto científico suscetível de gerar dilemas e controvérsias decorrentes de diferentes representações de caráter categorial, moral e legal de que é objeto (BOLTANSKI, 2013). De acordo com o autor, estes novos seres, que se enquadram na categoria de tecno-fetos, extravasam a taxinomia de qualificação assente numa dualidade feto autêntico (associado a um projeto parental) e feto tumoral (exterior a esse mesmo projeto). É identificável uma ampliação e fluidez de significados produzidos e de estatutos conferidos ao embrião humano in vitro, não o constituindo como uma entidade biológica estática e universal. No quadro desta complexificação das fronteiras da condição humana, os discursos no espaço público em torno da definição e estatuto do embrião humano - voltados para a sua proteção e uso - evidenciam justamente a pluralidade, incerteza e ambiguidade que caracterizam essas operações de qualificação do embrião segundo diferentes gramáticas publicamente disponíveis (BOLTANSKI, 2013; THÉVENOT, 2019). Essa discussão no espaço público transpõe-se também, por seu turno, para o espaço da clínica de procriação medicamente assistida, onde perspetivas técnico-científicas são suscetíveis de entrar em tensão com perspetivas humanizadoras do embrião na relação e comunicação entre profissionais (médicos e embriologistas) e progenitores dos embriões gerados em laboratório. 
dos diferentes estágios dos embriões, dos critérios de definição da sua qualidade e também das fases em que devem ser transferidos e em que número? Essa é uma questão complexa, pois existem vários sistemas de classificação (fato evidenciado inclusive nos discursos dos nossos entrevistados) e cada um deles se aplica a fases específicas do embrião e não à totalidade dos estágios de desenvolvimento embrionário. Isso significa que existem sistemas de classificação especializados em zigotos, em blastocistos ${ }^{3}$ etc.

2) Quais são os mecanismos de controle das práticas dos profissionais e de certificação dos procedimentos científicos e laboratoriais em termos de manipulação e transferência dos embriões criados em laboratório, no âmbito das técnicas de Procriação Medicamente Assistida (PMA) de $2^{\mathrm{a}}$ linha, nomeadamente Fertilização In Vitro (FIV) ou Injeção Intracitoplasmática de Espermatozoide (ICSI)?

3) De que modo os profissionais de saúde mais diretamente implicados nas técnicas laboratoriais - os embriologistas - (re)definem, integram e (re)apropriam os critérios e sistemas avaliativos e classificatórios do embrião humano nas suas práticas quotidianas?

Com base nos testemunhos de vários embriologistas entrevistados no quadro de um projeto de investigação em curso, apesar de haver o reconhecimento da existência e da importância dos procedimentos de estandardização, dos critérios de padronização e dos processos de normatização pretensamente universais e característicos das formas de regulação do conhecimento e da prática científicos, são também descritas diferentes modalidades de composição, adaptação, negociação, ressignificação e crítica dessas normatividades estandardizadas por parte dos profissionais de acordo com os seus próprios esquemas cognitivos, saberes experienciais e padrões normativos (culturais, ético-morais, religiosos etc.). A estas nuances na adesão e conformação à governança pela norma estão subjacentes determinadas justificações, que procuramos de igual modo investigar.

Uma forma de subjugação resulta da redução substancialista (THÉVENOT, 2010) das duas faces do envolvimento ante a garantia, correspondente ao momento de quietude, que é confundida com uma declaração fatual baseada num estado objetivo. A padronização atribui propriedades mensuráveis a objetos e entidades independentes, que se confundem com a an-

3 Do ponto de vista científico, o embrião enquanto estrutura celular pode ser dividido em três grandes fases: zigoto (célula que resulta da fecundação dos gâmetas), mórula (fase intermédia em que o embrião tem entre 16 e 32 células) e blastocisto (nível de organização celular mais complexo). 
siedade de realizar o bem que se procura, tornando-o real, e ameaçando dominar a dinâmica de familiarização com um conjunto fixo de rotinas às quais são atribuídas propriedades objetivas.

No entanto, as competências práticas de avaliação que os profissionais de saúde, em particular os embriologistas, souberam desenvolver e aplicar, a partir de um inventário de normas e convenções internacionalmente estabelecidas para lhes permitir avaliar os embriões nos seus diversos estágios, são por vezes suspensas, numa reformulação/revisão em termos deontológi$\cos$.

A forma como um embrião é classificado (que remete para a uma dimensão de estandardização como condição necessária à avaliação e comparabilidade) constitui o que Latour e Woolgar (1986) designam de inscrição literária, i.e., uma narrativa construída no âmbito de um ambiente ou quadro sociocultural segundo a própria mitologia do laboratório, incluindo os hábitos, as crenças, o conhecimento e a experiência, entre outros aspectos.

Por outro lado, nestes exercícios avaliativos, é importante considerar que o trabalho laboratorial dos embriologistas não se circunscreve à prossecução de procedimentos padronizados de formato cognitivo e moral exclusivo. Esses profissionais estão suscetíveis a questionar as normas padronizadas como dispositivos de suporte aos procedimentos em laboratório que, no trabalho de investimento em formas que subjaz à construção das guidelines em comissões científicas de padronização constituídas para o efeito (THÉVENOT, 2009), visam assumir uma condição neutra e objetiva. Isto é, as asserções inscritas na norma são elevadas a um estado de factualidade e indisputabilidade (não carecendo de explicação ou fundamentação) relativamente à realidade de que procuram dar conta e de dissociação do processo de criação e (potenciais) controvérsias científicas anteriormente existentes (LATOUR; WOOLGAR, 1986). Ora, o trabalho laboratorial na avaliação dos embriões não deixa, no entanto, de suscitar inquietações no embriologista, no quadro de uma abertura do olhar (THÉVENOT, 2019) para as condições em que esse standard foi produzido, podendo conduzir a operações de relegação do estado de factualidade e objetividade que a constituição da norma pressupõe. É o caso de operações de cotejamento com outras fontes de suporte da ação para lá das guidelines (e.g. artigos científicos, mas também juízos mais localizados a partir da experiência laboratorial acumulada ou elementos da trajetória clínica do casal ou beneficiária) que sustentam proposições divergentes/ complementares àquelas inscritas na norma e que, dessa forma, reduzem a factualidade e objetividade da norma-padrão (LATOUR; WOOLGAR, 1986). 


\section{MÉTODOS}

Este artigo baseia-se numa análise realizada a partir de dados recolhidos no âmbito de um projeto de investigação em curso que pretende: por um lado, analisar e descrever as formas de objetivação, avaliação e circulação de significados acerca do embrião humano in vitro entre especialistas e leigos, tanto na PMA quanto na investigação científica; e, por outro, esclarecer as dificuldades e dilemas enfrentados tanto por profissionais de saúde no desempenho das suas atividades quotidianas em medicina reprodutiva e em investigação com embriões humanos, como pelas mulheres ou casais que recorrem a determinadas técnicas de reprodução assistida de $2^{\mathrm{a}}$ linha (FIV e ICSI) e que, por exemplo, têm de lidar com o ônus da decisão sobre o destino a dar aos embriões excedentes criopreservados.

O projeto baseia-se numa abordagem mix-methods, que combina métodos quantitativos e qualitativos, nomeadamente entrevistas aprofundadas a beneficiários e a profissionais, um questionário on-line dirigido unicamente a beneficiários e ainda etnografia em centros de PMA. Infelizmente, devido às restrições impostas pela epidemia do SARS-CoV-2, ainda não nos foi possível realizar um trabalho etnográfico em contexto laboratorial no âmbito da procriação medicamente assistida para observar e descrever os processos que permitem a implementação de rotinas, a manipulação dos embriões, o recurso ao uso de tecnologia avançada com o objetivo de registrar a classificação dos embriões nas suas diversas fases.

Apesar de outros atores terem igualmente uma palavra a dizer acerca das decisões sobre os embriões, especificamente os médicos e os próprios beneficiários das técnicas (através do consentimento informado), para o presente artigo focamo-nos apenas nos discursos dos embriologistas em virtude de estarem encarregados da manipulação técnico-científica do embrião in vitro. Tomamos como base as entrevistas concedidas por 18 embriologistas de centros de PMA dos sectores público e privado, entre 25 de setembro de 2020 e 25 de janeiro de 2021, para o mesmo investigador. A confidencialidade dos dados e o anonimato dos participantes mediante codificação foram garantidos, tendo o consentimento informado sido obtido previamente à recolha das informações. Todas as entrevistas foram gravadas e transcritas ipsis verbis. A análise de conteúdo das entrevistas foi realizada com o apoio do software MaxQDA (versão 2018). 


\section{ENQUADRAMENTO E ESCOPO DE UMA PROFISSÃO: OS EMBRIOLOGISTAS CLÍNICOS}

Para enquadrar a análise que se segue, descrevemos as técnicas de PMA de $2^{\mathrm{a}}$ linha, como a FIV ou a ICSI, bem como as atribuições e tarefas desempenhadas pelos embriologistas no exercício da sua atividade profissional.

Após a estimulação do ovário, em que se procura obter vários folículos (em teoria, num folículo há um óvulo), procede-se à extração/aspiração dos óvulos/ovócitos (através de punção ovárica ou folicular) ou dos espermatozoides e à subsequente fecundação (junção dos gâmetas masculino e feminino) via FIV ou ICSI. Posteriormente, já em fase de laboratório, são realizadas as placas de cultura em que os óvulos fecundados darão origem a embriões que, sendo viáveis, serão transferidos com cinco ou seis dias de desenvolvimento para a cavidade uterina ou serão congelados, por contraposição aos embriões que não se desenvolvem ou que apresentam uma qualidade inferior (em termos de possibilidade de implantação e de prosseguir com uma gravidez), e que são depois descartados (ou seja, destruídos). A fecundação in vitro pode ser descrita como uma somatotécnica que evidencia o saber-fazer da reprodução na intersecção entre o biológico, o pessoal e a substância (MERLEAU-PONTY, 2017).

Aos embriologistas cabe toda a componente laboratorial que envolve a manipulação dos gâmetas e, posteriormente, dos embriões nos seus diferentes estágios: as suas incumbências profissionais vão desde a realização dos procedimentos inaugurais em termos de tratamento como a punção folicular e a preparação de esperma para inseminações intrauterinas, posteriormente as técnicas de fecundação como a FIV ou a ICSI, passando pelo acompanhamento do desenvolvimento embrionário até à seleção dos embriões a serem transferidos para a cavidade uterina, para serem criopreservados (em todos os estágios mas sobretudo no de blastocisto, i.e., o embrião de dia 5 , fase em que nem todos chegam num ciclo completo devido à probabilidade ser baixa) ou, pelo contrário, eliminados/descartados, e ainda as decisões sobre os congelamentos e descongelamentos (o que fazer quando não se consegue contatar o casal para confirmar a sua decisão quanto ao destino a dar aos embriões supranumerários). 


\section{TAXINOMIAS, GUIDELINES E A PREDOMINÂNCIA DO STANDARD}

No contexto da medicina reprodutiva, o processo de estandardização através da criação de vários sistemas de classificação equivalentes e da produção de um conjunto de guidelines normativas contribuiu para a governança pela norma, orientando a prática profissional dos embriologistas, bem como condicionando a existência e qualificação das próprias entidades vivas manipuláveis (os embriões).

Quando confrontados com a questão relacionada com a classificação da qualidade e avaliação da viabilidade dos embriões, assim como dos critérios determinantes para o sucesso da transferência para a cavidade uterina, alguns embriologistas entrevistados expressam, na sua resposta, um conteúdo técnico-científico, fazendo menção às taxinomias, às guidelines e aos standards internacionais que regulam e são usados na sua prática profissional, evidenciando uma relativa padronização dos procedimentos.

As taxinomias ou classificações embrionárias, enquanto indicadores de maior probabilidade de implantação (e consequente obtenção de gravidez), são diversas (as mais utilizadas são as classificações padronizadas pelo Consenso de Istambul e a da ASEBIR-Asociación para el Estudio de la Biología de la Reproducción ${ }^{4}$ ), e há correspondência entre elas em termos de graus $(1,2,3,4, \ldots$ ou A, B, C, D,...). Apesar da tentativa de unificação dos critérios, o fato de existirem vários sistemas de classificação embrionária e de nem todos os centros de PMA se regerem pelas mesmas guidelines, obriga a uma comparabilidade constante por parte dos embriologistas, especialmente quando questionados por beneficiários que fizeram tratamentos em outras unidades e que, como tal, trazem consigo essas taxinomias.

A descrição de alguns profissionais sobre a decisão acerca do destino a dar aos embriões (transferir, criopreservar ou descartar) circunscreve-se àquilo que é a avaliação técnica segundo critérios morfológicos (grau de fragmentação, estrutura celular etc.) e cinéticos (tempos de

\footnotetext{
4 Entre os diferentes sistemas de avaliação do embrião atualmente existentes - critérios e terminologia padronizada de classificação de oócitos, zigotos e embriões em contexto de laboratório de PMA-, identificam-se os que são elaborados por organizações profissionais internacionais e por associações de países individuais (MACHTINGER; RACOWSKY, 2013). Do lado dos sistemas de organizações profissionais internacionais identificam-se as guidelines de avaliação morfológica do Alpha Executive and ESHRE special Interest Group of Embryology, emanadas da reunião/workshop de um painel internacional de peritos científicos que teve lugar entre 26 e 27 de fevereiro de 2010, em Istambul (sendo o acordo alcançado denominado Consenso de Istambul). No grupo dos sistemas de países individuais encontra-se o da sociedade espanhola de profissionais que desenvolvem atividade no âmbito da biologia da reprodução humana, designada ASEBIR (MACHTINGER; RACOWSKY, 2013).
} 
divisão), evidenciando uma estrita vinculação às guidelines enquanto dispositivo de suporte ao procedimento. A avaliação do número e aspecto das células, bem como do desenvolvimento do embrião nos seus diversos estágios, é feita através da observação ao microscópio ou com recurso a equipamento mais sofisticado, como seja a incubadora com sistema time-lapse, que permite acompanhar o desenvolvimento embrionário em tempo real e facilita o trabalho de avaliação do embrião (possibilitando analisar a nível de timings de divisão através de um algoritmo e acompanhar diariamente o desenvolvimento do embrião através de imagens e vídeos). Outras questões relativas à ficha clínica ou à trajetória terapêutica dos beneficiários, ou outras fontes, são reservadas para a esfera da competência do médico, sendo o foco do embriologista a análise da estrutura celular em si.

Informação e conformidade, enquanto investimentos em formas (THÉVENOT, 1984, 1986) que geram formas do provável (THÉVENOT, 2002) associadas à grandeza industrial (BOLTANSKI; THÉVENOT, 2006) em termos de eficácia técnica (avaliação da qualidade e potencial de evolução do embrião) remetem para formas convencionais de coordenação da ação (entre embriologistas, médicos e beneficiários).

Alguns desses profissionais definem-se como "pragmáticos" (Entrevista B7.1), vinculando-se mais aos standards de avaliação técnico-científica dos embriões e procedimentos padronizados de seleção e rejeição, sem que essa decisão suscite em si qualquer tipo de inquietação. Como analisamos mais à frente, outros embriologistas introduzem uma maior complexidade de variáveis na descrição que fazem da tomada de decisão sobre os embriões gerados em laboratório (descarte, criopreservação, transferência etc.). Se a estandardização, ao produzir garantias públicas, em termos de regulação e objetividade, pode engendrar a pressão e opressão de um regime de envolvimento sobre outro (THÉVENOT, 2009), alguns embriologistas entrevistados contrariam essa sobreposição da norma padronizada mediante formas de envolvimento compósitas.

Todavia, entre esses profissionais mais vinculados à governação pela norma, não deixa de ser frequentemente relevado um único fator passível de intervir na sua ponderação enquanto embriologistas, em conciliação com aquilo que são os standards usados na avaliação morfológica do embrião. Concretamente, é quando o casal está no último ciclo de tratamento autorizado pela lei nas unidades de PMA públicas que pode ocorrer uma maior flexibilização na observação das normas padronizadas de avaliação, podendo o embriologista "forçar um bocadinho" a interpretação dessas diretrizes e permitir uma última oportunidade ao casal - na condição de que o embrião ou embriões em questão tenham uma "qualidade mínima" que ofereça ainda alguma possibilidade em termos de tratamento (Entrevista B8.2). No entanto, a "regra geral", 
enquanto formato cognitivo e avaliativo dominante, é seguir as normas, regras e protocolos usados na avaliação da qualidade morfológica do embrião.

Nestas aberturas à flexibilização, sempre refreadas, na observação da norma, na avaliação dos embriões e decisão laboratorial sobre o seu destino, alguns elementos relativos ao quadro clínico do casal/beneficiária podem excecionalmente ser levados em conta, como, por exemplo, o cenário limite de uma paciente ter zero embriões que cumprem rigorosamente os standards de avaliação de qualidade, podendo nesse caso a equipe de embriologistas reconsiderar a avaliação de alguns dos embriões. Nessas situações, as evidências científicas, de cariz industrial (mas não plasmadas nas normas padronizadas), de que embriões de menor qualidade podem resultar numa gravidez (mesmo com uma probabilidade muito baixa) sustentam o formato avaliativo parcialmente exterior às guidelines. Todavia, como convenção normativa preponderante, o quadro cognitivo e moral que idealmente deve orientar o olhar do embriologista na avaliação de cada embrião consubstancia-se numa pergunta fundamental: "Achas que esse embrião pode ou não dar uma gravidez? Sim ou não" (Entrevista B11). Elementos informativos relativos à trajetória clínica, como o paciente ter poucos embriões, devem ser preteridos - num esforço de depuração da situação, de forma a assegurar que a avaliação do embrião é feita o mais vinculadamente possível aos standards, evitando a intrusão de elementos externos, tidos como enviesantes, na medida em que oriundos de outros formatos de envolvimento, dessa avaliação do potencial e qualidade embrionária.

Esses discursos, no que diz respeito a esta dimensão particular de análise (influência do historial clínico do casal), apontam para formatos atuantes que parecem distanciar-se significativamente do caso de outros embriologistas que, como desenvolveremos mais à frente, referem mais vincadamente atender ao quadro psico-emocional do casal e de como um embrião, mesmo que de qualidade não elevada à luz da taxinomia de classificação mobilizada, pode ser selecionado mediante uma reapropriação segundo outros critérios avaliativos - nomeadamente, como esperança para os casais/beneficiários.

\section{O FEELING NO QUADRO DA DECISÃO OU A CRÍTICA À NORMA}

Ao longo do processo de realização das entrevistas, uma questão que inicialmente convidaria apenas a respostas padronizadas, de citação de normas-padrão internacionais usadas na avaliação da qualidade e classificação dos embriões, revela-se, todavia, um tema potenciador 
de controvérsias e um elemento de prova da pluralidade de posições no seio dos embriologistas.

Entre os embriologistas inquiridos, identificamos inicialmente quem estabelece uma dualidade entre o que é designado de fator humano e o algoritmo na tomada de decisão relativamente aos embriões a serem transferidos. Para além do conjunto de standards internacionais usados (em algumas clínicas são usados dois ou três modelos internacionais de avaliação morfo-cinética do embrião) é também evocado aquilo que é denominado o feeling do embriologista na decisão relativamente aos embriões a transferir. Por outro lado, a par dessa decisão co-suportada por uma rotina composta de um saber-fazer adquirido pela aprendizagem e acumulação de experiências (BREVIGLIERI, 2006), através de uma familiaridade com o contexto laboratorial que extravasa uma mediação da ação (exclusivamente) por normas institucionalizadas (THÉVENOT, 2006), há igualmente o recurso a estudos realizados que evidenciam alguma não linearidade entre classificações e critérios convencionados de avaliação dos embriões e o efetivo desenvolvimento embrionário, ou seja, evidências científicas que sugerem maior prudência numa confiança absoluta nas normas padronizadas relativamente ao desenvolvimento embrionário.

Para além das guidelines, a seleção dos embriões a transferir ou a descartar depende também assim do elemento humano, i.e., do juízo feito pelo embriologista e do seu feeling, adquirido através da experiência na observação e avaliação do desenvolvimento em laboratório dos embriões. Sobretudo no caso dos embriões passíveis de serem classificados de borderline, ou seja, cuja qualidade está naquilo que se designa de "área cinzenta" (Entrevista B13), sem uma orientação taxativa das guidelines, essa dimensão subjetiva quanto à viabilidade do embrião, que radica na experiência e se manifesta na forma de feelings do embriologista, adquire maior peso nas decisões sobre os embriões a rejeitar ou a incluir no conjunto dos transferíveis.

No quadro destas possíveis composições entre formatos de envolvimento do embriologista em laboratório, consoante se deposita confiança nas convenções públicas (garantia), nas propriedades funcionais (planificação) ou nos usos familiares (hábito ou rotina), assim essas três situações diferem na possibilidade de serem generalizáveis, comunicáveis ou comunalizadas (THÉVENOT, 2009). É o caso do cotejamento entre a avaliação do embrião suportada pela rotina e pelo standard enquanto referenciais distintos de suporte à coordenação da ação: "olhamos para o desenvolvimento embrionário de outro que tem uma classificação menor e ficamos na dúvida: '[...] Este parece-me mais bonito, mas aquele tem uma classificação melhor”' (Entrevista B10).

Reforçando esta pluralidade compósita no uso dos standards como suporte da ação, a relação destes embriologistas com as guidelines de avaliação dos embriões pode igualmente sofrer evoluções ao longo dos anos. Se, numa fase inicial da carreira, o embriologista cinge-se 
estritamente a essas normas padronizadas, com o tempo, e à medida que vai expandindo o olhar para outras variáveis de aferição do embrião - como a avaliação morfocinética (sobretudo com o recurso à incubadora time-lapse) -, acaba por constatar que o tempo de desenvolvimento do embrião não corresponde inteiramente ao que está descrito nas guidelines. Esse desfasamento - a constatação, através do conhecimento empírico e da experiência, de que as instruções nas guidelines e as suas classificações estáticas não se ajustam totalmente, por exemplo, à evolução morfocinética do embrião que se observa em laboratório - pode conduzir a um abrir os olhos (THÉVENOT, 2019) relativamente à validade da norma-padrão como dispositivo (exclusivo) de suporte à ação. As lógicas atuantes do embriologista abrem-se assim ao uso de feelings enquanto referencial, mais localizado, de coordenação da ação alicerçado na própria experiência profissional, e que servem de suporte a um discernimento mais customizado na tomada de decisão sobre os embriões. Essa operação avaliativa é sustentada igualmente por um trabalho de consulta de outras fontes científicas (como artigos publicados) com orientações que estão para lá do que está já oficialmente incorporado nas guidelines, isto é, conhecimento científico que não foi ainda objeto de um trabalho de investimento em formas, de construção de procedimentos, indicadores e benchmarks definidores da norma padronizada por grupos/comitês científicos constituídos para o efeito (THÉVENOT, 2009).

Ainda no que se refere à relação dos embriologistas com os standards de avaliação do embrião, alguns entrevistados manifestam uma perspetiva crítica relativamente àquilo que é considerado ser a posição maioritária dos embriologistas na classificação do embrião: a de uma vinculação excessiva às classificações/taxinomias e ao uso que delas fazem nas decisões sobre os embriões (transferir, criopreservar, descartar etc.). Nestas visões críticas, esta posição distinta daquela que é observada noutros embriologistas é atribuída, em primeiro lugar, aos anos de experiência profissional (associando em parte uma maior vinculação aos standards de avaliação por parte dos embriologistas com menos anos de experiência). Por outro lado, essas diferenças na adesão vincada às guidelines são imputadas também a um uso dos standards como instrumento de afirmação dos embriologistas enquanto grupo ocupacional perante o saber médico, numa lógica de salvaguarda e legitimação da sua área de jurisdição profissional (ABBOTT, 1988).

Estes entendimentos críticos evidenciam, pois, uma tensão estrutural entre as duas faces da convenção, entre a adesão e confiança cega nas formas convencionais de qualificação/avaliação e, por outra, a dúvida e inquietude perante a conformidade à norma e à contestação da validade dos standards (por causa da sua uniformidade disciplinadora), abrindo-se espaço para outros regimes de envolvimento (THÉVENOT, 2009). 


\section{A VISÃO HOLÍSTICA DO PROCESSO E O ENVOLVIMENTO EM PROXIMIDADE}

No quadro de outros envolvimentos compósitos, para além daquilo que são os standards, guidelines e normas padronizadas de avaliação da qualidade, potencial e viabilidade de cada embrião, a seleção daqueles que são para transferir, congelar e descartar não é, para alguns embriologistas, totalmente alheada daquilo que são as particularidades da trajetória clínica do casal. É o caso, por exemplo, de um casal com uma longa trajetória de ciclos falhados. Mesmo que a avaliação de acordo com os standards seja a de que um dos embriões produzidos não se desenvolverá (logo, recomendando que seja descartado), a decisão do profissional, enquanto embriologista, pode ser a sua criopreservação, para posterior transferência. Essa decisão assenta não (exclusivamente) numa avaliação probabilística daquilo que é o seu potencial de desenvolvimento (ou seja, segundo critérios de eficácia), mas tendo em conta o que aquele embrião de reserva, congelado, pode significar para o casal. Os embriologistas desenvolvem assim um trabalho emocional em que, para além de terem de gerir os seus próprios estados emocionais, consideram como objetos de cuidado tanto os materiais reprodutivos (pelos quais são responsáveis e depositários) como os beneficiários dos tratamentos, por quem sentem empatia (FITZGERALD; LEGGE; FRANK, 2013). Deste modo, um embrião, mesmo que de qualidade não elevada à luz da taxinomia de classificação mobilizada, pode ser selecionado mediante outros critérios avaliativos. Pode ser nomeadamente reapropriado por significar uma esperança, no quadro de uma abertura hospitaleira, nesse trabalho de classificação, à gestão do impacto de um hipotético insucesso (como é a não implantação de um embrião após transferência) e à gestão da inquietude associada ao incerto na concretização do objetivo da gravidez que acompanha o envolvimento do casal no plano terapêutico (THÉVENOT, 2006).

Da mesma forma que em relação aos juízos co-suportados por envolvimentos familiares, alguns entrevistados descrevem mesmo como a sua prática foi evoluindo desde o início da sua atividade profissional no sentido de abertura à inclusão da trajetória clínica do casal na ponderação feita. Se, inicialmente, e de acordo com aquilo que é preconizado por várias guidelines, qualquer embrião catalogado como não viável (e.g., abaixo da classificação B ou C) seria por default descartado, com o tempo vai-se flexibilizando aquilo que é a avaliação e respetiva decisão sobre o embrião (transferir, criopreservar e descartar). De resto, esta colagem paulatinamente menos vincada à norma padronizada enquanto suporte convencional de envolvimento é sustentada por uma justificação industrial, sobretudo em artigos científicos que fornecem 
evidências sobre as possibilidades (ainda que menores) de desenvolvimento dos embriões com classificação mais baixa, reforçando o carácter compósito de uma avaliação que não perde o seu vínculo a critérios de legitimidade industrial (eficácia de procedimentos).

No que concerne a outros elementos que são mobilizáveis na decisão em torno do embrião humano, a avaliação envolve igualmente outras informações plasmadas na ficha clínica do casal/beneficiário, logo no quadro de lógicas atuantes na relação com os beneficiários mais distantes de formatos de envolvimento de proximidade. A decisão de transferir, congelar e descartar pode ser condicionada também por aquilo que é a trajetória e o historial clínico do casal, como a idade da mulher ou o número de tratamentos/ciclos de transferência já realizados. É o caso hipotético de um casal em final da idade legalmente prevista para um tratamento no setor público $^{5}$, em que um embrião com qualidade média é passível de ser avaliado de forma distinta de um casal/beneficiária com idade favorável e/ou perspetiva de vários ciclos de tratamento ainda realizáveis.

É o caso também do cenário de um ciclo de tratamento no setor público que constitui a última oportunidade de um casal concretizar a gravidez, na qual pode ganhar mais relevo a apropriação do embrião como derradeira tentativa (distinto, portanto, do formato de envolvimento de maior proximidade associado à conceção do embrião como esperança). Como os entrevistados salvaguardam, esta inflexão no juízo avaliativo relativamente à norma padronizada é feita quer sem detrimento da fundamentação industrial da decisão clínica (i.e., não é transferível um embrião sem suporte científico relativamente às suas efetivas possibilidades de implantação) quer sem prejuízo do rigor na transmissão de informação ao casal sobre as efetivas probabilidades de obtenção de gravidez, assegurando uma decisão autónoma e informada enquanto princípio normativo orientador da relação profissional-beneficiário (THÉVENOT, 2019).

O formato de envolvimento destes embriologistas na sua atividade profissional revela-se, pois, suscetível de assumir formas compósitas, articulando, por um lado, as guidelines com uma ação em proximidade, expressa numa atenção parcial às singularidades de cada casal, em termos de trajetória terapêutica e até de dimensão psicológica e emocional (angústia, ansiedade, sofrimento etc.) ou, por outro lado, a procura da manutenção de um distanciamento técnico-cientifico, em termos de objetividade nas decisões tomadas, co-mediada por outros dispositivos de ação à distância (como a ficha clínica/registo clínico), logo mais apartados de

5 No quadro jurídico regulador da PMA em Portugal, o limite máximo para recurso a tratamentos com financiamento público, para a mulher (limite máximo é inexistente para o parceiro masculino), é de 40 anos para as técnicas de segunda linha - fertilização in vitro (FIV) e microinjeção intracitoplasmática de espermatozoide ICSI) - ou antes dos 42 anos da mulher no caso da inseminação artificial. 
envolvimentos de proximidade com os beneficiários (apropriados neste caso na generalidade, como casos clínicos).

Em ambas as lógicas atuantes compósitas na articulação dos standards, a ação surge sempre enquadrada como orientada pela eficácia na execução das diferentes técnicas e procedimentos laboratoriais, enquanto formato cognitivo e avaliativo. Sobrepõe-se, assim, o foco no sucesso na obtenção de uma gravidez e consequente concretização do projeto parental dos casais, sendo que mesmo aberturas a envolvimentos de proximidade continuam a exigir uma capacidade doseada, convenientemente calibrada, de dissociação entre a vertente emocional e a vertente técnico-científica, da qual depende, na opinião dos próprios embriologistas, a sua competência enquanto profissionais - a sua grandeza industrial.

\section{AS CONVENÇÕES E A COORDENAÇÃO DA AÇÃO NO QUADRO DA INCERTEZA}

No que diz respeito ao trabalho de avaliação do embrião, do ponto de vista da sua qualidade e potencial, mesmo quando os embriologistas afirmam cingir-se aos standards de classificação usados na respectiva instituição, pode surgir, todavia, um elemento de incerteza e até de subjetividade por parte do próprio profissional. Esta noção de incerto constitui uma construção ao nível do regime de ação em plano (THÉVENOT, 2006), que o restringe na sua garantia de realização. A dimensão de incerteza remete para a dúvida ou receio quanto à confiabilidade dos resultados dos procedimentos (por exemplo, se um determinado embrião irá resistir ou não à congelação/descongelação) e adequabilidade das próprias decisões tomadas individualmente (se um determinado embrião considerado não viável é mesmo para descartar).

A imprevisibilidade dos resultados das técnicas biomédicas de reprodução assistida caracteriza assim o contexto de trabalho destes profissionais, dando lugar ao medo, à ansiedade e à frustração. Nas situações marcadas pela ausência de garantia, os embriologistas socorrem-se de formas de avaliação/medição da incerteza e de modalidades de gestão da mesma, não obstante as tensões críticas que originam (THÉVENOT, 1995), como seja a confiança por referência aos casos (improváveis) de sucesso e a relativização das promessas fundamentadas na estatística (taxas de sucesso). Uma das formas de superar as eventuais dúvidas e de evitar o elevado peso da decisão individual é a consulta interpares, na tentativa de alcançar um consenso a nível da decisão. 
No quadro da ideia de projeto e do indivíduo comprometido/envolvido em plano, associada ao cálculo, autonomia, responsabilidade, escolha e governo por objetivos (THÉVENOT, 2010), no caso específico da concretização de uma gravidez após transferência do embrião criado in vitro, surge igualmente a assunção de uma perspectiva precaucionária, devido ao risco, à incerteza e à ansiedade permanente daí gerada. Tal concepção manifesta-se quer na criopreservação de todos os embriões considerados viáveis quer no prolongamento da cultura até ao blastocisto - até ao limite permitido pelas normas - daqueles embriões que se situam no que é designado de "área cinzenta” (Entrevista B13).

Surge em alguns discursos a tentativa de reduzir o peso da classificação embrionária, associada à qualidade, i.e., baseada no desenvolvimento celular e no grau de fragmentação, na decisão sobre os embriões a transferir, congelar ou descartar. A não ser que determinados indícios/indicadores inquestionáveis à luz das guidelines estejam presentes (existência de anomalias, elevada fragmentação e fraco ou nulo desenvolvimento), torna-se difícil prever com acuidade a capacidade ou grau de implantação do embrião após transferência e se o mesmo irá ou não originar uma gravidez. Esta avaliação é atualmente facilitada pelo recurso a instrumentos tecnológicos de elevada precisão, como o time-lapse.

Na verdade, não obstante a padronização dos procedimentos laboratoriais, o cumprimento das guidelines e a adequação da ação em função dos standards internacionalmente aceitos, prevalece, todavia, um elemento de incerteza ao nível da coordenação da ação, principalmente quanto ao resultado das técnicas em termos de fecundação e evolução embrionária in vitro e in utero. Fatores como o número de ovócitos extraídos, a sua fertilização ou não, as formas de evolução e o nível de qualidade (sobretudo genética) dos embriões que resultam dos gâmetas fecundados determinam o desenrolar da própria prática dos profissionais, em articulação - em alguns casos - com as decisões a tomar pelos próprios beneficiários.

Os momentos de decisão sobre os embriões a selecionar para descartar/destruir ${ }^{6}$ são inquietantes para alguns dos nossos entrevistados, especialmente quando eles os concebem como potencial de vida, mais do que um conjunto/aglomerado de células. Essa concepção reflete-se na própria forma como esses profissionais desenvolvem o seu trabalho laboratorial. Vários embriologistas referiram que, antes de tomar a decisão de descartar, muitas vezes prolongam a cultura in vitro dos embriões até ao $5^{\circ}, 6^{\circ}$ ou $7^{\circ}$ dia, para que a observação do desenvolvimento celular não deixe margem para dúvidas de que o potencial de desenvolvimento do embrião é

6 A transferência dos embriões não suscita essa inquietação, uma vez que o sucesso já não depende de qualquer intervenção e decisão humana. 
inexistente e de que ele não é efetivamente viável. Esses profissionais não descartam nenhum embrião até todas as possibilidades científicas sobre a qualidade de desenvolvimento e implantação estarem afastadas, mobilizando a sua faceta mais sentimental, humanista e de empatia com os beneficiários. Há quem, inclusive, se qualifique como "otimista" (em termos de confiança) na aferição que faz de cada embrião, procurando descartar sempre o menor número possível, estendendo a cultura in vitro enquanto for cientificamente sustentável, embora o propósito seja sempre encontrar o "vencedor" ou "special one" (Entrevista B12). Os embriões, enquanto entidades tecnocientíficas manipuláveis, suscitam não só um motivo de preocupação em termos éticos e políticos (LATOUR, 2003), mas são sobretudo objeto de cuidados (BELLACASA, 2010) por parte desses embriologistas.

No entanto, o otimismo, traduzido numa maior latitude na interpretação da norma padronizada, é contrabalançado pelo que é descrito como "honestidade intelectual" (Entrevista B12), no sentido de um não desvinculamento do critério industrial no trabalho de avaliação da potencialidade de cada embrião (por exemplo, não aproveitando embriões de qualidade duvidosa para futura transferência). Nesta composição de regimes de envolvimento, além da eficácia como bem visado, são igualmente considerados os custos adicionais a nível físico e emocional (além de financeiro) nos beneficiários associados aos insucessos na obtenção de gravidez.

No que concerne à conceção do embrião como conjunto de células, mas com elevado potencial de gerar uma vida, este formato cognitivo e avaliativo na relação do embriologista com o embrião também é suscetível de evoluir, reconfigurar-se, ao longo da trajetória profissional, sendo que inicialmente a perda de embriões pode suscitar um maior impacto a nível emocional. À luz desta concepção do embrião enquanto células com elevado potencial, dissociada de uma perspectiva mais estritamente funcional do embrião, a destruição pode suscitar particular inquietação no profissional. Essa inquietude surge, não pelos embriões em si mesmos, no quadro de uma singularização humanizadora, mas pela sua concepção, na generalidade, à luz de diferentes gramáticas do bem comum (BOLTANSKI, 2013): enquanto bem precioso e passível de doação, seja pelo seu potencial de concretização do projeto parental de outros casais ou mesmo pela sua utilidade/utilização ao serviço de projetos científicos com interesse coletivo ${ }^{7}$. De resto,

7 Ao nível da bioética, existe todo um debate acerca do estatuto do embrião humano, a partir do qual se pode refletir sobre questões como a humanidade e o início da vida, cujas fronteiras não são consensuais, mas alvo de disputa e de tensão, sobretudo entre dois posicionamentos contraditórios, embora não sem ambiguidades e cambiantes. Por falta de espaço neste artigo, não poderemos aprofundar este tópico, mas não queremos deixar de apresentar de seguida os dados de dois estudos relativos ao contexto português no sentido de enquadrar os contornos desta discussão. A análise dos argumentos expostos em documentos regulamentares produzidos por comissões de ética a nível nacional sobre a (i)licitude da investigação em embriões humanos revela diferentes estatutos e classificações atribuídas ao embrião criopreservado: por um lado, é uma "neoestrutura biológica" ou um "artefacto laboratorial", 
no domínio daquilo que são as inquietações na atividade em laboratório, há situações em que o “apego" em alguns casais pode refletir-se no próprio trabalho laboratorial, por exemplo patente num maior "nervosismo" (Entrevista B16) na execução de determinada técnica.

No caso dos embriologistas que concebem o embrião como "conjunto de células" e um "instrumento de trabalho" (Entrevista B13), esse entendimento reflete-se no envolvimento do embriologista com o embrião. Nesses casos, nenhuma componente do trabalho laboratorial que envolva a manipulação do embrião, mesmo a sua destruição, é passível de suscitar no profissional algum tipo de inquietação, na medida em que é considerada uma inevitabilidade. No entanto, no decurso da atividade, surgem "dúvidas" sobre as decisões que são tomadas relativamente ao destino dado a cada embrião, no sentido de uma incerteza no quadro do regime de ação em plano relativamente à possibilidade de terem sido descartados embriões potencialmente viáveis, passíveis de gerar uma gravidez, na sequência do trabalho avaliativo mediado pelos standards: "Nós provavelmente já deitámos muitos bebés fora" (Entrevista B13). Entre os entrevistados, há quem inclusive faça explicitamente a distinção entre dúvida e inquietação na descrição que elabora da sua experiência na execução dos vários procedimentos envolvendo o embrião - distinção que reforça a avaliação do embrião enquanto material laboratorial, objeto de procedimentos padronizados, sem abertura a outros formatos de envolvimento e consequentes dilemas morais (THÉVENOT, 2019).

Outro aspecto a reter prende-se com a diversidade de posicionamentos relativamente à definição do estágio de desenvolvimento do embrião em que deve ser feita a transferência para a cavidade uterina, que decorre quer da diferença de escolas de pensamento, quer de condicionalismos a nível técnico. Há centros que transferem ao $3^{\circ}$ dia, outros ao $5^{\circ}$ dia (fase de blastocisto) e casos ainda em que se prolonga a cultura in vitro até ao $6^{\circ}$ ou $7^{\circ}$ dia de desenvolvimento embrionário.

Apesar da tendencial padronização, não existe unanimidade entre os embriologistas quanto à definição de boas práticas, sendo de salientar que, ao nível do debate bioético, determinadas técnicas de PMA são objeto de controvérsia e discussão na comunidade científica. É o caso de práticas/técnicas de PMA que podem conduzir ao desperdício de embriões (como

o que remete para uma categorização de cariz biológico ou técnico; por outro, é um "ser humano" ou uma "pessoa" com dignidade e direito a proteção e respeito (ALVES; MACHADO; SILVA, 2013). No âmbito do nosso estudo, foi possível identificar, quanto aos beneficiários, quatro grandes metáforas acerca do estatuto do embrião criado in vitro: os embriões são considerados como possibilidades de sucesso nos tratamentos; ou são percecionados enquanto utilidades que podem ser objeto de controle de propriedade e disposição; ou são encarados como descendência em potencial com a qual os futuros progenitores estabelecem antecipadamente laços familiares e emocionais; ou incorporam uma contra-dádiva para a ciência ou outros beneficiários, em resposta à generosidade de profissionais ou dadores de gâmetas (DELAUNAY; SANTOS; GOUVEIA, 2021). 
as culturas embrionárias que duram até ao $5^{\circ}$ dia, em vez do $3^{\circ}$ dia, podendo levar à perda de embriões que, caso fossem transferidos mais cedo para o útero, poderiam ter mais hipótese de sobreviver e resultar numa gravidez) ou o recurso a técnicas que representam maiores riscos para o embrião - como é o caso da banalização da ICSI, em preterição da FIV, motivada por interesses financeiros (sendo uma técnica mais cara) e, pelo seu carácter invasivo, que representa mais riscos para a saúde do embrião.

A decisão sobre o número de embriões a transferir para a cavidade uterina também constitui um momento de incerteza para alguns dos embriologistas entrevistados, em que são tidos em consideração vários fatores. O CNPMA recomenda a transferência de apenas um embrião, sobretudo em mulheres com menos de 35 anos, num primeiro ciclo de tratamento, no sentido de evitar gravidezes múltiplas e os consequentes inconvenientes e riscos associados, como sejam a prematuridade e a mortalidade perinatal. "O gold standard clínico de transferir um embrião" (Entrevista B9). No entanto, em casos em que o prognóstico seja mau (em virtude de ciclos anteriores falhados) e a idade da mulher seja mais avançada (por volta dos 40 anos), a opção pode ser a de transferir dois embriões para aumentar as probabilidades de gravidez, em termos de taxas de sucesso. Apesar do número máximo de embriões a transferir seja decidido na fase ex ante ao início dos tratamentos, durante a assinatura do consentimento informado pelos beneficiários, pode ser, todavia, renegociado entre o casal, o clínico e o embriologista, em fase posterior, previamente à transferência, de acordo com a avaliação da qualidade embrionária. $\mathrm{Na}$ avaliação, feita pelo médico, das razões clínicas que impedem ou desaconselham a transferência de mais de um embrião, no sentido de evitar uma gravidez gemelar, para além da idade, acrescem outros fatores igualmente associados à mulher, como a baixa estatura ou a sua cavidade uterina. O corpo biológico da mulher é, pois, um critério também a ser levado em conta no processo de decisão sobre a transferência embrionária, no que diz respeito à sua condição etária e fisiológica.

\section{GRAMÁTICA DAS LÓGICAS PROFISSIONAIS POR REFERÊNCIA À NORMA}

Como temos vindo a descrever e a analisar, observam-se flutuações ou oscilações nas formas dos embriologistas se relacionarem com as normas padronizadas na avaliação e classificação dos embriões em função do contexto e da sua postura individual. 
Em articulação com a avaliação da qualidade, potencial e viabilidade dos embriões segundo taxinomias convencionadas, guidelines internacionais e normas padronizadas (em termos de eficácia das práticas), surge igualmente a referência a critérios práticos subjacentes à escolha dos embriões para transferir, criopreservar ou descartar e que, por vezes, decorrem da própria interação com os casais. Os embriologistas diferenciam vários critérios: 1) clínico-científico (profissionais); 2) psicoemocional (utentes); 3) socioeconômico (utentes), 4) financeiro (institucional, sobretudo no setor público); e 5) estatístico (taxas de sucesso, sobretudo no setor privado). No que se refere à avaliação da qualidade dos embriões - e à decisão sobre quais transferir, congelar ou eliminar - ocorrem assim situações em que existe uma ponderação entre o critério clínico-científico (a norma padronizada nas guidelines internacionais) e o critério humano (o feeling pessoal do profissional decorrente da sua própria experiência ou a consideração pelo estado emocional do casal).

Com o intuito de sistematizar os vários matizes em termos de atitudes, posicionamentos e formas de relação, mais ou menos rígidos, dos embriologistas perante a norma, i.e., relativamente aos standards de avaliação e à classificação dos embriões, propomos uma gramática de lógicas profissionais: a lógica "by the book", a lógica empírico-intuitiva, a lógica crítica, a lógica contemporizadora, a lógica precaucionária elou otimista. Embora qualquer categorização acabe por ter um efeito redutor da pluralidade encontrada, permite, porém, estruturar melhor a informação produzida.

No quadro da lógica "by the book", os embriologistas escudam-se no enquadramento legal e em normas padronizadas e critérios técnico-científicos emanados das instâncias de regulação no domínio da PMA enquanto dispositivos de suporte à ação. Para tal, é fundamental o fato de encarar o embrião como mero material biológico, i.e., como um conjunto ou aglomerado de células, cuja principal função é a concretização de uma gravidez bem-sucedida e consequente realização do projeto parental. Para alguns embriologistas, este registro de obediência à norma vai inclusive no sentido de evitar dilemas éticos ou morais no exercício da sua atividade profissional, no que diz respeito ao conjunto de técnicas e procedimentos médicos e laboratoriais de manipulação dos embriões.

O que designamos de lógica empírico-intuitiva remete-nos para a ideia de um conhecimento adquirido pela prática, de um saber de experiência feito, que se exprime na sensibilidade do profissional (“palpites” sobre os embriões), logo não traduzível em guidelines, i.e., padronizável. Apesar dos entrevistados falarem na componente feeling/intuição, o que à partida parece reportar-se ao mundo inspirado, a descrição que fazem do que entendem por esse feeling remete para uma capacidade de ajuizar a partir da experiência prática acumulada ao longo dos anos. Esse conhecimento, que não é sistematizável na forma de guidelines, articula-se com o próprio método científico e até mesmo se lhe opõe enquanto ideia de método.

Encontramos igualmente aquilo a que chamamos de lógica crítica associada a uma postura 
mais vincadamente distanciada dessas normas de avaliação naquilo que é a minúcia na classificação do embrião, apresentando inclusive uma perspectiva abertamente de reprovação dos embriologistas que trabalham numa lógica mais “by the book". Há quem pois manifeste um certo posicionamento crítico ao que consideram uma dependência excessiva da maioria dos embriologistas relativamente aos standards de avaliação (classificações e taxinomias) na tomada de decisão sobre os embriões. No entanto, é de salientar o impacto da dimensão temporal, visto que vários embriologistas afirmam que a sua relação com os standards foi evoluindo ao longo do tempo, à medida que foram ganhando experiência (por exemplo, com o tal feeling ou a intuição a ganharem mais peso na avaliação dos embriões).

Paralelamente, surge a relativização das taxinomias em termos de classificação morfológica dos embriões e a referência à intervenção de outras variáveis não captáveis pelos métodos convencionalmente institucionalizados, sobretudo pelas tecnologias de visualização biomédica (que não indica a qualidade genética do embrião). Acresce a questão da influência, na tomada de decisão acerca dos embriões a transferir, congelar ou descartar, da própria trajetória terapêutica e historial clínico do casal (por exemplo a idade da mulher e o número de ciclos de tratamento passíveis de realizar dentro dos preceitos legais e regulamentares que enquadram a PMA). Tal remete-nos para uma lógica contemporizadora.

Por fim, a lógica precaucionária elou otimista prende-se com a questão da inquietação decorrente do elemento humano na tomada de decisão sobre o embrião in vitro e as modalidades de minorar essa inquietude. Alguns embriologistas, no quadro da realização das técnicas e procedimentos laboratoriais, decidem prolongar o tempo de cultura até ao $5^{\circ}$ dia para comprovar efetivamente a inviabilidade e fraca qualidade do embrião de acordo com as taxinomias e classificações orientadoras da prática. A essa postura de precaução na condução da ação está subjacente ao receio de descartar embriões ainda com potencial de desenvolvimento. Salientamos ainda a referência ao modo como esses desassossegos poderão um dia vir a ser suprimidos com a evolução tecnológica e a crescente automatização dos procedimentos, com base em algoritmos.

Mesmo entre membros que compõem uma mesma equipe de embriologistas, é possível identificar três perspectivas e posturas distintas relativamente àquilo que é a relação com os dispositivos científico-normativos de avaliação de desenvolvimento embrionário. No trabalho de avaliação do potencial de cada embrião, há quem se situe a si próprio na posição intermédia entre colegas mais transigentes na interpretação científica da viabilidade dos embriões e outros que, nos seus juízos, tendem a cingir-se mais estritamente àquilo que são os standards de avaliação e a literatura científica para fundamentar as decisões. É visível como, não obstante todo o conjunto de dispositivos de suporte à decisão em torno do embrião - como standards e algoritmos -, existe margem para diferentes perspectivas sobre as decisões a tomar nos vários estágios de desenvolvimento embrionário. Assiste-se à criação de arranjos compósitos de compromisso que combinam elementos contrastantes envolvendo diferentes formatos de 
informação e avaliação para apaziguar as tensões críticas no exercício da profissão.

A construção social do conhecimento ou dos fatos científicos acerca do desenvolvimento embrionário e do modo como o trabalho laboratorial é realizado sobre os embriões envolve processos de inscrição e tradução, bem como o desenvolvimento de associações e redes de relações complexas e heterogêneas entre actantes, i.e., entre entidades humanas e não humanas (LATOUR; WOOLGAR, 1986]; LATOUR, 2005), como seja, embriologistas, beneficiários de PMA, gâmetas, embriões, corpos, taxinomias, leis, artigos científicos, tecnologias de alta precisão, entre outros.

A título conclusivo, gostaríamos apenas de destacar alguns pontos; por um lado, a dimensão processual (localização num continuum em termos de desenvolvimento) associada aos diferentes estatutos morais e ontológicos do embrião; por outro, a diferenciação a nível conceptual entre viabilidade (potencial de desenvolvimento) do embrião e a sua qualidade (grau avaliado em termos objetivos segundo critérios morfológicos, cinéticos e genéticos), o que de certa forma estabelece uma oposição entre uma conceção dinâmica e uma conceção estática do embrião (em formação). Acresce outra dimensão relevante ao nível do exercício da atividade profissional, que é a distinção entre dúvida - que remete para uma componente técnico-científica nas decisões a tomar segundo uma gramática industrial assente na eficácia - e inquietação - de cariz ético e moral relacionada com a perceção da decisão considerada moralmente aceitável e em prol do bem comum, portanto inserida no quadro de uma gramática cívica.

Por fim, quanto às dinâmicas profissionais, é de salientar a diferenciação entre instituições ao nível do estabelecimento e negociação de fronteiras e áreas de jurisdição (ABBOTT, 1988), em termos de distribuição de tarefas e papéis entre embriologistas e médicos no contexto da medicina reprodutiva. Tal diferenciação reflete-se no tipo (informação quantitativa, abstrata e genérica versus qualitativa, detalhada e individualizante) e frequência (diária ou pontual) da comunicação dos embriologistas com os pacientes em relação ao processo envolvendo gâmetas e embriões, no quadro de novas - e cada vez mais complexas e especializadas - intervenções tecnológicas e médico-científicas. "Enquanto houver vida no laboratório daquele casal, nós contactamos o casal diariamente" (Entrevista B4). Esta variabilidade nas modalidades de comunicação dos embriologistas com os beneficiários pode estar na base das diferenças na forma desses profissionais se (re)apropriarem das guidelines e de abertura ou não a dinâmicas de vinculação, no quadro de um regime de proximidade, aos casais/beneficiários, embora tal variável organizacional não constitua o único elemento explicativo. Outro aspecto determinante poderá ser a propensão maior para um trabalho técnico, de investigação, em contexto laboratorial ou, pelo contrário, um gosto particular por um trabalho mais prático e em regime de proximidade com os casais beneficiários em termos de interação. Os contextos locais - i.e., a forma como os embriologistas de diferentes laboratórios concebem e selecionam os embriões e interagem com os beneficiários - condicionam o sentido e a evolução do naturalismo científico da biologia da reprodução, naquilo que pode ser designado de relação 
operatória, enquanto encadeamento de ações orientadas para um fim (a concepção e o nascimento de um bebê) (MERLEAU-PONTY, 2018).

\section{REFERÊNCIAS}

1. ABBOTT, A. The System of Professions: An Essay on the Division of Expert Labor. Chicago: The University of Chicago Press, 1988.

2. ALVES, B. R.; MACHADO, H.; SILVA, S. Reflexões sobre investigação em embriões de origem humana: o debate nas organizações de ética portuguesas. História, Ciências, Saúde-Manguinhos, v. 20, suppl.1, p. 1137-1151, 2013. Disponível em: https://www. scielo.br/j/hcsm/a/d9xjwrr36S7bjFrcs37ZqvM. Acesso em: 18 mar. 2017.

3. BELLACASA, M. P. Matters of Care in Technoscience: Assembling Neglected Things. Social Studies of Science, v. 4, n. 1, p. 85-106, 2010. Disponível em: https://journals. sagepub.com/doi/10.1177/0306312710380301. Acesso em: 07 mai. 2020.

4. BOLTANSKI, L. The Foetal Condition: A Sociology of Engendering and Abortion. Cambridge: Polity Press, 2013.

5. BOLTANSKI, L.; THÉVENOT, L. On Justification: Economies of Worth. Princeton: Princeton University Press, 2006.

6. BREVIGLIERI, M. Le fond ténébreux de la routine: à propos des morales du geste technique au travail. In: LAUGIER, S.; GAUTIER, C. L'ordinaire et le politique. Paris: PUF, 2006. p. 189-217.

7. ClARKE, A. E.; SHIM, J. K.; MAMO, L.; FOSKET, J. R.; FISHMAN, J. R. Biomedicalization: Technoscientific Transformations of Health, Illness, and U.S. Biomedicine. American Sociological Review, v. 68, n. 2, p. 161-194, 2003. Disponível em: https://www.jstor.org/stable/1519765. Acesso em: 14 abr. 2020.

8. DELAUNAY, C.; SANTOS, M; GOUVEIA, L. In Vitro Metaphors: ART Beneficiaries' Meaning-Making on Human Embryos in the Context of IFV in Portugal. Reproductive Biomedicine \& Society Online, 2021. Disponível em: https:/www.rbmsociety.com/ article/S2405-6618(21)00017-4/fulltext?dgcid=raven_jbs_aip_email. Acesso em: 29 jun. 2021.

9. DICAGLIO, S. Staging Embryos: Pregnancy, Temporality and the History of the Carnegie Stages of Embryo Development. Body \& Society, v. 23, n. 2, p. 3-24, 2017. Disponível em: https://journals.sagepub.com/doi/abs/10.1177/1357034X17697801?journalCode=boda. Acesso em: 21 jan. 2020. 
10. ESHRE TASK FORCE ON ETHICS AND LAW. I. The Moral Status of the PreImplantation Embryo. Human Reproduction, v. 16, n. 5, p. 1046-1048, 2001. Disponível em: https://academic.oup.com/humrep/article/16/5/1046/2913514. Acesso em: 21 jul. 2020.

11. FITZGERALD, R. P.; LEGGE, M.; FRANK, N. When Biological Scientists become Health-Care Workers: Emotional Labour in Embryology. Human Reproduction, v. 28, n. 5, p. 1289-1296, 2013. Disponível em: https://academic.oup.com/humrep/ article/28/5/1289/943482. Acesso em: 21 abr. 2020.

12. LATOUR, B.; WOOLGAR, S. Laboratory Life: The Construction of Scientific Facts. Princeton: Princeton University Press, 1986.

13. LATOUR, B. Reassembling the Social: An Introduction to Actor-Network-Theory. Oxford: Oxford University Press, 2005.

14. LATOUR, B. Why Has Critique Run Out of Steam? From Matters of Fact to Matters of Concern. Critical Inquiry, v. 30, n. 2, p. 25-248, 2003. Disponível em: http://www. bruno-latour.fr/sites/default/files/89-CRITICAL-INQUIRY-GB.pdf. Acesso em: 14 mar. 2021.

15. MACHTINGER, R.; RACOWSKY, C. Morphological Systems of Human Embryo Assessment and Clinical Evidence. Reproductive BioMedicine Online, v. 26, n. 3, p. 210-221, 2013. Disponível em: https://www.rbmojournal.com/article/S14726483(12)00700-6/fulltext. Acesso em: 05 dec, 2020.

16. MERLEAU-PONTY, N. Sélectionner des embryons humains: Une relation opératoire au sein de laboratoires de biologie de la reproduction en Inde et en France. L'Homme, v. 225, p. 101-124, 2018. Disponível em: https://journals.openedition.org/lhomme/30724. Acesso em: 14 out. 2020.

17. MERLEAU-PONTY, N. Féconder in vitro dans des laboratoires en Inde et en France: Une Somatotechnique ? Ethnologie française, v. 47, n. 3, p. 511-520, 2017. Disponível em: https://www.cairn.info/revue-ethnologie-francaise-2017-3-page-509.htm. Acesso em: 14 out. 2020.

18. THÉVENOT, L. Rules and Implements: Investment in Forms. Social Science Information, v. 23, n.1, p. 1-45, 1984. Disponível em: https://journals.sagepub.com/ doi/10.1177/053901884023001001. Acesso em: 12 fev. 2016.

19. THÉVENOT, L. Les investissements de formes. In: THÉVENOT, L. (ed.). Conventions économiques. Paris: Presses Universitaires de France, 1986. p. 21-71.

20. THÉVENOT, L. Émotions et évaluations dans les coordinations publiques. In: PAPERMAN, P.; OGIEN, R. (org.). La couleur des pensées: émotions, sentiments, intentions. Paris: l'EHESS, 1995. p. 145-174.

21. THÉVENOT, L. Which Road to Follow? The Moral Complexity of an "Equipped" 
Humanity. In: LAW, J.; MOL, A. (org.). Complexities: Social Studies of Knowledge Practices. Durham: Duke University Press, 2002. p. 53-87.

22. THÉVENOT, L. L’Action au pluriel. Sociologie des régimes d'engagement. Paris: Éditions La Découverte, 2006.

23. THÉVENOT, L. Governing Life by Standards. Social Studies of Science, v. 39, n. 5, p. 793-813, 2009. Disponível em: https://www.researchgate.net/publication/240707725 Governing_Life_by_Standards_A_View_from_Engagements. Acesso em: 22 fev. 2018.

24. THÉVENOT, L. Individualités entre émancipation, pouvoir et oppression. In: CORCUFF, P.; LE BART, C.; SINGLY, F. (org.). L'individu aujourd'hui. Rennes: Presses Universitaires de Rennes, 2010. p. 289-300.

25. THÉVENOT, L. What Engages? The Sociology of Justifications, Conventions, and Engagements, Meeting Norms. La Revue des droits de l'homme, n. 16, 2019. Disponível em: http://journals.openedition.org/revdh/7114. Acesso em: 14 nov. 2020.

\section{Catarina Delaunay}

Investigadora integrada do Centro Interdisciplinar de Ciências Sociais da Universidade Nova de Lisboa. Formação Acadêmica. Doutora em Sociologia, especialidade de Sociologia da Cultura, na Faculdade de Ciências Sociais e Humanas da Universidade Nova de Lisboa. ID ORCID: https://orcid.org/0000-0001-9679-0681. E-mail: catarinadelaunay@fcsh.unl.pt. Colaboração: Conceção e delineação do projeto de investigação, Análise e interpretação de dados, Pesquisa bibliográfica, Conceção da estrutura do artigo, Redação.

\section{Luís Gouveia}

Investigador integrado do Centro Interdisciplinar de Ciências Sociais da Universidade Nova de Lisboa. Doutor em Sociologia pela Universidade Nova de Lisboa. ID ORCID: https://orcid. org/0000-0002-6518-2330. E-mail: lgouveia@fcsh.unl.pt. Colaboração: Pesquisa empírica, Análise e interpretação de dados, Redação. 